\title{
Interactive comment on "The Eulerian urban dispersion model EPISODE. Part II: Extensions to the source dispersion and photochemistry for EPISODE-CityChem v1.2 and its application to the city of Hamburg" by Matthias Karl et al.
}

Matthias Karl et al.

matthias.karl@hzg.de

Received and published: 8 May 2019

We thank Referee \#2 for positive evaluation of the manuscript. Below we reply to the comments.

1. EPISODE is a dispersion model for application in urban settings, including chemical reactions. The manuscript describes the architecture of the EPISODE model very carefully and in detail. Tests on modules (e.g., photochemistry) are performed, and described to very successful in terms of producing reasonable 
results in agreement with previous model and literature data, and referenced to sample data. The model is applied to the domain Hamburg. It is quite impressive how various sources of data sets are utilized in order to achieve the best possible model output. Eventually, the model fulfills performance objectives for the most important air pollutants and can thus be used for regulatory applications. The authors also propose how the model can be further improved in the future. It is a fine contribution that should be published.

Reply: We thank the Reviewer for their assessment of the scope and methodology of the manuscript and the applicability of the EPISODE-CityChem model.

2. There are only a few minor issues this reviewer want to raise: a) page 1 , line 27: replace "nitrogen oxide" by "nitric oxide"

Reply: Thank you. We excuse the mistake in the chemical name of NO. Further, we changed on page 5, line 26, "hydrogen peroxy radical" to "hydroperoxyl radical" (HO2).

2. b) page $7, \mathrm{R} 8 \mathrm{a}$ is not balanced. Do you want to say: $\mathrm{HCHO}+2 \mathrm{O} 2+\mathrm{hv}=\mathrm{CO}$ $+2 \mathrm{HO} 2$ ?

Reply: R8a was unbalanced with respect to oxygen atoms. Oxygen is usually ignored on the reactant side when setting up chemical equations for the numerical ODE solver because the mixing ratio of oxygen in the atmosphere is not affected by this reaction to any significant extent. The photolysis of formaldehyde in the radical channel gives $\mathrm{HCHO}+\mathrm{hv}=>\mathrm{H}+\mathrm{HCO}$. The hydrogen atom $(\mathrm{H})$ quickly combines with $\mathrm{O} 2$ to form $\mathrm{HO} 2$ and the intermediate formyl radical $(\mathrm{HCO})$ reacts very rapidly with $\mathrm{O} 2$ to yield $\mathrm{HO} 2$ and $\mathrm{CO}$. We correct this equation as written by the reviewer to fulfil the balance for oxygen atoms.

2. c) page 7, R10 is not balanced. Do you want to say: $\mathrm{OH}+\mathrm{CO}+\mathrm{O} 2=\mathrm{HO} 2+$ $\mathrm{CO} 2$ ?

Printer-friendly version

Reply: R10 was unbalanced with respect to oxygen atoms. We correct this equation

Discussion paper 
as written by the reviewer to fulfil the balance for oxygen atoms.

2. d) page 18, line 21: What is meant with "urban albedo and conductivity"? Do you mean heat conductivity of surface material?

Reply: Albedo and conductivity are material properties referring to urban surfaces such as concrete/asphalt/roofs. Urban albedo means the surface albedo in cities, i.e. the ability of urban surfaces to reflect solar radiation. Urban surface albedo values in TAPM are based on Oke (1988; table 2 therein). Urban conductivity here means thermal conductivity, which is a measure of the ability of a surface material to conduct or transmit heat. A surface material with a high thermal conductivity will transfer heat at a higher rate than a material having a low thermal conductivity.

For clarity, we have replaced "urban albedo and conductivity" by "albedo of urban surfaces and thermal conductivity of urban surface materials, e.g. concrete/asphalt/roofs".

\section{References:}

Oke T. R.: The urban energy balance, Progress in Physical Geography, 12, 471-508, https://doi.org/10.1177/030913338801200401, 1988.

Interactive comment on Geosci. Model Dev. Discuss., https://doi.org/10.5194/gmd-2018-325, 2019. 